\title{
Induced Systemic Resistance in Arabidopsis thaliana Against Pseudomonas syringae pv. tomato by 2,4-Diacetylphloroglucinol-Producing Pseudomonas fluorescens
}

\author{
David M. Weller, Dmitri V. Mavrodi, Johan A. van Pelt, \\ Corné M. J. Pieterse, Leendert C. van Loon, and Peter A. H. M. Bakker
}

First author: United States Department of Agriculture-Agricultural Research Service, Root Disease and Biological Control Research Unit, Pullman, WA 99164-6430; second author: Department of Plant Pathology, Washington State University, Pullman 99164-6430; and third, fourth, fifth, and sixth authors: Plant-Microbe Interactions, Institute of Environmental Biology, Utrecht University, Padualaan 8, $3508 \mathrm{CH}$ Utrecht, The Netherlands.

Accepted for publication 8 December 2011.

\begin{abstract}
Weller, D. M., Mavrodi, D. V., van Pelt, J. A., Pieterse, C. M. J., van Loon, L. C., and Bakker, P. A. H. M. 2012. Induced systemic resistance in Arabidopsis thaliana against Pseudomonas syringae pv. tomato by 2,4diacetylphloroglucinol-producing Pseudomonas fluorescens. Phytopathology 102:403-412.

Pseudomonas fluorescens strains that produce the polyketide antibiotic 2,4-diacetylphloroglucinol (2,4-DAPG) are among the most effective rhizobacteria that suppress root and crown rots, wilts, and damping-off diseases of a variety of crops, and they play a key role in the natural suppressiveness of some soils to certain soilborne pathogens. Root colonization by 2,4-DAPG-producing $P$. fluorescens strains Pf-5 (genotype A), Q2-87 (genotype B), Q8r1-96 (genotype D), and HT5-1 (genotype N) produced induced systemic resistance (ISR) in Arabidopsis thaliana accession Col-0 against bacterial speck caused by $P$. syringae pv. tomato. The ISR-eliciting activity of the four bacterial genotypes was

similar, and all genotypes were equivalent in activity to the well-characterized strain $P$. fluorescens WCS417r. The 2,4-DAPG biosynthetic locus consists of the genes phlHGF and phlACBDE. phlD or phlBC mutants of Q2-87 (2,4-DAPG minus) were significantly reduced in ISR activity, and genetic complementation of the mutants restored ISR activity back to wild-type levels. A phlF regulatory mutant (overproducer of 2,4-DAPG) had ISR activity equivalent to the wild-type Q2-87. Introduction of DAPG into soil at concentrations of 10 to $250 \mu \mathrm{M} 4$ days before challenge inoculation induced resistance equivalent to or better than the bacteria. Strain Q2-87 induced resistance on transgenic NahG plants but not on npr1-1, jarl, and etrl Arabidopsis mutants. These results indicate that the antibiotic 2,4-DAPG is a major determinant of ISR in 2,4-DAPGproducing $P$. fluorescens, that the genotype of the strain does not affect its ISR activity, and that the activity induced by these bacteria operates through the ethylene- and jasmonic acid-dependent signal transduction pathway.
\end{abstract}

Isolates of Pseudomonas fluorescens that produce the antibiotic 2,4-diacetylphloroglucinol (2,4-DAPG) can be isolated from the rhizosphere environment of many plant species $(24,38,39,64,65)$ and even marine environments (22). Within this group of bacteria, 22 distinct genotypes (A-T, PfY, and PfZ) have been described so far by either repetitive sequence-based polymerase chain reaction (rep-PCR) using the BOXA1R primer (BOX-PCR); restriction fragment length polymorphisms (RFLP) of phlD, a key gene in the 2,4-DAPG biosynthetic locus ( $p h l H G F$ and phlACBDE); or phylogenetic analyses based on phlD sequences (9,30,31,37-39); however, several more genotypes occur (B. B. Landa and D. M. Weller, unpublished data).

2,4-DAPG-producing $P$. fluorescens isolates have been the subject of intense investigation because of their biocontrol activity against a wide range of plant pathogens $(8,11,15,17,23,50,54,64)$ when applied as seed and soil treatments, and because they are responsible for the suppressiveness of certain soils against take-all disease of wheat $(12,49,64)$, caused by Gaeumannomyces graminis var. tritici, and black root rot of tobacco $(51,65)$, caused by Thielaviopsis basicola. 2,4-DAPG-producing pseudomonads also

Corresponding author: D. M. Weller; E-mail address: wellerd@wsu.edu

http://dx.doi.org/10.1094/PHYTO-08-11-0222

This article is in the public domain and not copyrightable. It may be freely reprinted with customary crediting of the source. The American Phytopathological Society, 2012. are enriched in the rhizospheres of wheat (65), pea (30), and flax (31) during monoculture to densities exceeding the threshold density required for pathogen suppression $\left(10^{5} \mathrm{CFU} \mathrm{g} \mathrm{g}^{-1}\right.$ of root) (49), suggesting that these bacteria have a widespread role in plant protection $(64,65)$.

2,4-DAPG has broad antiviral, antibacterial, antifungal, antihelminthic, and phytotoxic properties $(4,22,27,28,54)$. The key role that this antibiotic plays in disease suppression has been demonstrated both by studies using genetic mutational analysis with P. fluorescens strains CHA0, F113, Q8r1-96, Q2-87, and SSB17 $(12,18,23,54,63)$ and by direct isolation of the antibiotic from rhizospheres colonized by these bacteria $(7,23,47)$. 2,4DAPG may either inhibit soilborne pathogens directly $(7,8,11,12$, $22,27,49)$ or induce systemic resistance in the host plant $(21,56)$.

Rhizobacteria-mediated induced systemic resistance (ISR) is the ability of certain root-colonizing, nonpathogenic plant growth-promoting rhizobacteria to enhance (prime) the defensive capacity of the host against subsequent pathogen infection of foliage and roots that are spatially separated from the roots colonized by the inducing rhizobacteria (59). ISR is phenotypically similar to pathogen-induced systemic acquired resistance (SAR); both phenomena provide systemic resistance, reduce disease symptoms, inhibit pathogen growth in plant tissues, and operate in a variety of plant species (59). ISR acts through salicylic acid (SA)-dependent (10) or SA-independent mechanisms (44) and, in the latter, the signal transduction pathway is ethylene (ET) and jasmonic acid (JA) dependent. 
Pseudomonas rhizobacteria activate ISR through different mechanisms that can be both complementary and additive and vary depending upon the pathosystem used as the assay (59). Bacterial determinants of ISR vary among pseudomonads $(3,62)$ and include cell envelope components such as lipopolysaccharides $(33,40,61)$ and flagella (40), antibiotics $(1,21)$, lipopeptides $(41,58)$, and iron-regulated metabolites such as siderophores $(1,13,32,34,40)$ and SA $(6,10,34)$. However, in some cases, SA may not function individually but, rather, is required as part of an SA-containing siderophore $(3,52)$.

Iavicoli et al. (21) reported that root inoculation of Arabidopsis thaliana accession Columbia with $P$. fluorescens $\mathrm{CHA} 0$ protected leaves from Hyaloperonospora arabidopsidis and that production of 2,4-DAPG was required for ISR activity. Siddiqui and Shaukat (56) reported that 2,4-DAPG produced by CHA0 also induced systemic resistance in tomato against the root-knot nematode, Meloidogyne javanica. Strain CHA0 is a well-described 2,4-DAPG producer belonging to ARDRA group 1 and BOX-PCR genotype A $(24,39,64)$ and produces a broad spectrum of bioactive metabolites in addition to 2,4-DAPG, including the antibiotics pyrrolnitrin and pyoluteorin (64). Strain CHA0 is very similar to the well-described strain Pf-5, whose genome has been sequenced (42).

The purpose of this study was to determine the ability of other genotypes of 2,4-DAPG producers to induce resistance in $A$. thaliana against bacterial speck caused by $P$. syringae pv. tomato and to identify the role that 2,4-DAPG plays in ISR activity. We demonstrated that $P$. fluorescens strains Pf-5, Q2-87, Q8r1-96, and HT5-1, representing four genotypes (A, B, D, and N, respectively), induced resistance to a similar level in Arabidopsis, and that these strains were equivalent in disease suppression to $P$. fluorescens WCS417r, a well-know ISR inducer. We also showed a key role for the antibiotic in ISR by these bacteria through a genetic mutational analysis of strain Q2-87 and direct application of 2,4-DAPG to the soil. A preliminary account of this work was previously published (66).

\section{MATERIALS AND METHODS}

Bacterial cultures and inoculum. Bacterial strains and plasmids used in this study are described in Table 1. 2,4-DAPGproducing P. fluorescens strains Pf-5, Q2-87, Q8r1-96, and HT5-1 were selected as inducers of resistance because they were isolated from three geographically different regions of the United States (Texas, Pf-5; Washington, Q2-87 and Q8r1-96; and Minnesota, HT5-1) and they represent two ARDRA groups (Pf-5, group 1; Q2-87, Q8r1-96, and HT5-1, group 2) and four genotypes (A, B, $\mathrm{D}$, and N, respectively). P. fluorescens WCS417r (non-2,4-DAPG producer) was used as an ISR-positive control because it induces resistance in carnation, radish, and $A$. thaliana $(45,60)$. The virulent bacterial pathogen $P$. syringae pv. tomato DC3000 (67), causal agent of bacterial speck, was the challenge pathogen. An avirulent derivative of DC3000 (avrRpt2), carrying plasmid pLAFR3 containing the avirulence gene avrRpt2 (67), was used to induce SAR. Escherichia coli strain JM109 was used for all cloning experiments. Mutants and genetically complemented mutants of Q2-87 were prepared as described below, except for the 2,4-DAPG-minus mutant Q2-87::Tn5-1, which was previously constructed by Bangera and Thomashow (4). All strains except $E$. coli were rifampicin resistant, stored at $-80^{\circ} \mathrm{C}$, and cultured on King's medium B (KB) (25) or Luria-Bertani (LB) (2) agar or broth at $28^{\circ} \mathrm{C}$ or $37^{\circ} \mathrm{C}$. Antibiotic supplements were used at the following concentrations: ampicillin, 40 or $100 \mu \mathrm{g} \mathrm{ml}{ }^{-1}$; rifampicin, $75 \mu \mathrm{g} \mathrm{ml}^{-1}$; tetracycline, 12.5 or $25 \mu \mathrm{g} \mathrm{ml}^{-1}$; kanamycin, $50 \mu \mathrm{g} \mathrm{ml}^{-1}$; chloramphenicol $\left(13 \mu \mathrm{g} \mathrm{ml}^{-1}\right)$; and cycloheximide $\left(100 \mu \mathrm{g} \mathrm{ml}^{-1}\right)$.

Bacterial inoculum for ISR assays was prepared essentially as previously described (45). Briefly, for soil inoculations, inducer

TABLE 1. Bacterial strains and plasmids used in this study

\begin{tabular}{|c|c|c|}
\hline Strain or plasmid & Relevant characteristics ${ }^{\mathrm{y}}$ & Source or reference \\
\hline \multicolumn{3}{|l|}{ Strains } \\
\hline Pseudomonas fluorescens $\mathrm{Pf}-5$ & 2,4-DAPG ${ }^{+}$Rif $^{r}$ Genotype $\mathrm{A}^{\mathrm{z}}$ & 20 \\
\hline P. fluorescens Q8r1-96 & 2,4-DAPG ${ }^{+}$Rif $^{\mathrm{r}}$ Genotype $\mathrm{D}^{\mathrm{z}}$ & 49 \\
\hline P. fluorescens HT5-1 & 2,4-DAPG ${ }^{+}$Rif $^{r}$ Genotype $N^{z}$ & 39 \\
\hline P. fluorescens Q2-87 & 2,4-DAPG ${ }^{+}$Rif $^{\mathrm{r}}$ Genotype $\mathrm{B}^{\mathrm{z}}$ & 63 \\
\hline P. fluorescens Q2-87::Tn5-1 & 2,4-DAPG ${ }^{-} \operatorname{Rif}^{\mathrm{r}} \operatorname{Kan}^{\mathrm{r}}$ phlD::Tn5 & 4 \\
\hline P. fluorescens Q2-87BC & 2,4-DAPG ${ }^{-}$Rif $^{\mathrm{r}} \Delta p h l C B:: \mathrm{Tet}^{\mathrm{r}}$ & This study \\
\hline P. fluorescens Q2-87D & 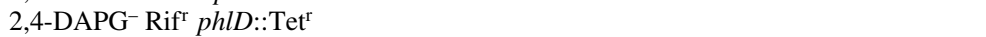 & This study \\
\hline P. fluorescens Q2-87BCZ & 2,4-DAPG ${ }^{-}$Rif $^{\mathrm{r}} \Delta p h l C B:: l a c Z$ & This study \\
\hline P. fluorescens Q2-87DZ & 2,4-DAPG- Rif $^{\mathrm{r}}$ phlD::lacZ & This study \\
\hline P.fluorescens Q2-87F & 2,4-DAPG ${ }^{+}$Rif $^{\mathrm{r}} p h l F:: \mathrm{Tet}^{\mathrm{r}}$ & This study \\
\hline P. fluorescens WCS417r & 2,4-DAPG ${ }^{-}$Rif $^{\mathrm{r}}$ & 60 \\
\hline P. syringae pv. tomato DC 3000 & Rif $^{\mathrm{r}}$ & 67 \\
\hline P. sryingae pv. tomato DC3000 avrRpt 2 & Rif $^{\mathrm{r}}$ pLAFR 3 containing avrRpt 2 & 67 \\
\hline Escherichia coli JM109 & 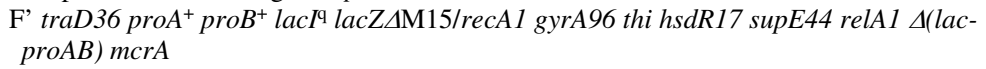 & Promega Corp. \\
\hline E. coli $\mathrm{S} 17-1(\lambda$-pir $)$ & 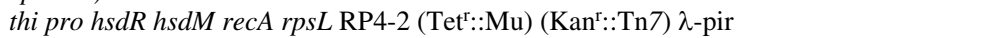 & 57 \\
\hline \multicolumn{3}{|c|}{ 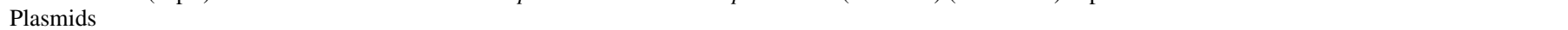 } \\
\hline pBluescript II KS & ColE1 f1(+) bla & Stratagene \\
\hline pALTER-Ex 1 & ColE1 Tet ${ }^{\mathrm{r}} \mathrm{SP} 6, t a c$, and $\mathrm{T} 7$ promoters & Promega Corp. \\
\hline pNOT19 & ColE1 bla accessory plasmid & 53 \\
\hline pMOB3 & $\mathrm{Kan}^{\mathrm{r}}$ cat oriT $\operatorname{sacBR}$ & 53 \\
\hline pSKS104 & Source of promoterless lacZYA genes, ColE1 bla & 55 \\
\hline pMON5122 & RK2 Tet $^{\mathrm{r}}$, pRK415 containing $7.08 \mathrm{~kb}$ BamHI-XbaI fragment with phlACBDE genes & 4 \\
\hline pPHL5122 & pVS1 Kan ${ }^{\mathrm{r}}$, pVSP41 containing $7.08 \mathrm{~kb}$ BamHI-XbaI fragment with phlACBDE genes & 4 \\
\hline pMON5123 & RK2 Tet $^{\mathrm{r}}$, pRK415 containing $4.67 \mathrm{~kb}$ BamHI fragment with phlACBD genes & 4 \\
\hline pNOT- $\Delta$ NcoI-Tc ${ }^{r}-\mathrm{MOB}$ & pNOT19 containing phlCB::Tet ${ }^{\mathrm{r}}$ fusion ligated with MOB cassette & This study \\
\hline pNOT-SalI-Tcr-MOB & pNOT19 containing phlD::Tet ${ }^{\mathrm{r}}$ fusion ligated with MOB cassette & This study \\
\hline pNOT-SacI-Tcr-MOB & pNOT19 containing $p h l F::$ Tet $^{\mathrm{r}}$ fusion ligated with MOB cassette & This study \\
\hline pNOT- $\Delta$ NcoI-lacZ-MOB & pNOT19 containing phlCB::lacZ fusion ligated with MOB cassette & This study \\
\hline pNOT-SalI-lacZ-MOB & pNOT19 containing phlD::lacZ fusion ligated with MOB cassette & This study \\
\hline
\end{tabular}

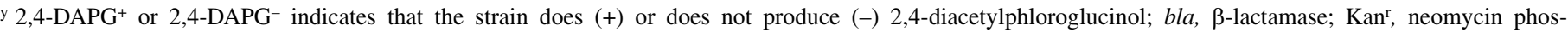
photransferase; tet or Tet $^{\mathrm{r}}$, tetracycline resistance; cat, chloramphenicol transferase; Rif ${ }^{\mathrm{r}}$, rifampin resistance.

${ }^{\mathrm{z}}$ Genotypes were defined earlier by BOX polymerase chain reaction fingerprinting (39). 
bacteria were grown for 24 to $36 \mathrm{~h}$ on $\mathrm{KB}$ at $28^{\circ} \mathrm{C}$; cells from the plates were harvested into sterile $10 \mathrm{mM} \mathrm{MgSO}$, washed, and suspended in $10 \mathrm{mM} \mathrm{MgSO}$; and the concentration was appropriately adjusted based on optical density at $660 \mathrm{~nm}$. $P$. syringae pv. tomato and avirulent $P$. syringae pv. tomato were grown for 20 to $24 \mathrm{~h}$ in $\mathrm{KB}$ broth, harvested by centrifugation, and suspended in $10 \mathrm{mM} \mathrm{MgSO}_{4}$ and the concentration was appropriately adjusted.

DNA manipulations. Plasmid DNA isolation, restriction enzyme digestion, agarose gel electrophoresis, ligation, and E. coli transformation were carried out according to standard protocols (2). Electroporation of Pseudomonas spp. was performed according to Enderle and Farwell (16) with a Bio-Rad Gene Pulser system (Bio-Rad Laboratories, Hercules, CA). PCR amplifications were carried out with Taq DNA polymerase (Promega Corp., Madison, WI) according to the manufacturer's recommendations. DNA sequencing was performed with an ABI Prism BigDye Terminator v.3.0 Ready Reaction Cycle Sequencing Kit (Applied Biosystems, Foster City, CA). Oligonucleotide primers were designed with Oligo 6.0 software (Molecular Biology Insights, Inc., Cascade, $\mathrm{CO}$ ) and sequence data were analyzed with the OMIGA 2.0 software (Accelrys, San Diego, CA).

Construction of 2,4-DAPG biosynthetic and regulatory mutants. P. fluorescens Q2-87 2,4-DAPG-deficient mutants (Q287D, Q2-87BC, Q2-87DZ, and Q2-87BCZ), and regulatory mutant Q2-87F were generated by using a gene-replacement system described by Schweizer (53). To generate P. fluorescens Q2-87D and $P$. fluorescens Q2-87BC, a 4.67-kb BamHI fragment of pMON5123 containing phlACBD (4) was subcloned into pBluescript II KS (Stratagene, La Jolla, CA). To generate the phlCB knockout, the plasmid was digested with $N c o$ I and polished with a Klenow fragment of DNA polymerase I. The 517-bp NcoI fragment containing portions of the $p h l C$ and $p h l B$ genes was then replaced with a $2.5-\mathrm{kb} P v u \mathrm{II}$ fragment bearing a tetracycline resistance gene from pALTER-Ex1 (Promega Corp.) (Fig. 1). Similarly, to generate the phlD knockout, the tetracycline resistance determinant from pALTER-Ex1 was introduced into the unique SalI site within the phlD gene. The interrupted inserts were subcloned into pNOT19, and the plasmid was then digested with $N o t \mathrm{I}$ and ligated with a 5.3-kb pMOB3 $s a c B$ cassette. To construct $P$. fluorescens Q2-87F, a 2.6-kb EcoRV fragment of pMON5123 containing phlF and phlA was subcloned into pNOT19, and the tetracycline resistance determinant from pALTER-Ex1 was introduced into the unique $S a c$ I site within the phlF gene. The resulting plasmids (pNOT- $\Delta$ NcoI-Tc ${ }^{r}-\mathrm{MOB}$, pNOT-SalI-Tc ${ }^{\mathrm{r}}-$ $\mathrm{MOB}$, and pNOT-SacI-Tc $\left.{ }^{\mathrm{r}}-\mathrm{MOB}\right)$ were mobilized into $P$. fluorescens Q2-87 through mating with E. coli S-17 ( $\lambda$-pir). Transconjugants were selected on LB agar supplemented with rifampicin at $75 \mu \mathrm{g} / \mathrm{ml}$ and tetracycline at $25 \mu \mathrm{g} / \mathrm{ml}$, and selection for double crossovers was carried out on LB agar supplemented with 5\% sucrose. Following selection, all isolates were screened for the absence of plasmid-borne markers by Southern hybridization and PCR with specific primers (36).
P. fluorescens Q2-87BCZ and P. fluorescens Q2-87DZ strains were constructed essentially as described above, except that a 5.3$\mathrm{kb}$ SalI fragment from pSKS104 containing promoterless lacZYA genes was used to interrupt the phlCB and phlD genes (Fig. 1). The resulting plasmids, $\mathrm{pNOT}-\Delta$ NcoI-lacZ-MOB and pNOT-SalIlacZ-MOB, were mobilized into $P$. fluorescens Q2-87 through mating with $E$. coli S-17 ( $\lambda$-pir). The integrity of the fusions was confirmed by DNA sequencing, PCR, and Southern hybridization. Overnight incubation of $P$. fluorescens Q2-87DZ and P. fluorescens $\mathrm{Q} 2-87 \mathrm{BCZ}$ on $\mathrm{KMB}$ agar supplemented with $\mathrm{X}_{\text {gal }}$ and DAPG resulted in formation of blue colonies (data not shown).

Complementation of $P$. fluorescens $\mathbf{Q 2 - 8 7 D Z}$ and $P$. fluorescens Q2-87BCZ. For complementation studies, broad-hostrange recombinant plasmids pMON5122 and pPHL5122 (Table 1) that bear phlACBD genes were introduced into strains $Q 2-$ 87DZ and Q2-87BCZ by electroporation. Following the initial round of selection on LB agar supplemented with tetracycline or kanamycin, several randomly picked individual colonies were used to start cultures in $\mathrm{KB}$ broth. After $48 \mathrm{~h}$ of growth at $28^{\circ} \mathrm{C}$, all cultures were analyzed for 2,4-DAPG and MAPG production by using high-performance liquid chromatography (HPLC) as described previously $(4,7)$.

Cultivation of plants and inoculation. A. thaliana wild-type accession Col-0, transgenic NahG (impaired in SA-dependent defense response), and mutants nprl-1 (impaired in both SA- and JA/ET-dependent defense responses), etr-1 (ET insensitive), and jarl (JA insensitive) (14) were grown as previously described $(26,52)$, with some modifications. These mutants were used to help determine the plant hormone signaling involved in ISR. Seed were germinated in plastic trays (14 by $29 \mathrm{~cm}$ ) containing $2 \mathrm{~kg}$ of sterile quartz sand, supplemented with $200 \mathrm{ml}$ of half-strength Hoagland nutrient solution (HNS) (19) containing $10 \mu \mathrm{M} \mathrm{Fe}-$ ethylene-diamine di-o-hydroxyphenylacetic acid (FeEDDHA) (Syngenta, Basel, Switzerland). Seed were sprinkled on the top of the sand and misted with water. The trays were placed in larger covered trays $(28.5$ by $43.5 \mathrm{~cm})$ to maintain the relative humidity at $100 \%$ and incubated in a climate chamber or greenhouse with an 8-h day and 16-h night cycle at 24 and $20^{\circ} \mathrm{C}$, respectively, and at 60 to $70 \%$ relative humidity. Seedlings (10 to 14 days old) were individually transplanted into $60-\mathrm{ml}$ plastic pots (one seedling/ pot), each containing $\approx 100 \mathrm{~g}$ of a potting soil/sand mixture, which was autoclaved twice for $30 \mathrm{~min}$ and then supplemented with HNS + FeEDDHA (50 ml/kg of mix) and with either $10 \mathrm{mM}$ $\mathrm{MgSO}_{4}$ with bacteria $\left(10^{9} \mathrm{CFU} \mathrm{ml}{ }^{-1}\right)$ or an equal amount of $10 \mathrm{mM} \mathrm{MgSO}_{4}$ as a control $(50 \mathrm{ml} / \mathrm{kg}$ of mix). Pots were placed in the large trays, and the seedlings were grown for an additional 3 weeks in the climate chamber. HNS + FeEDDHA was applied to the pots once a week, and tap water was given when needed.

ISR bacterial treatments consisted of wild-type strains, mutants, and genetically complemented mutants of strain Q2-87 thoroughly distributed throughout the potting mix (introduced bacteria at $5 \times 10^{7} \mathrm{CFU} \mathrm{g^{-1 }}$ of mix). Pure 2,4-DAPG also was tested for ISR activity at concentrations of 10,100 , and $250 \mu \mathrm{M}$.

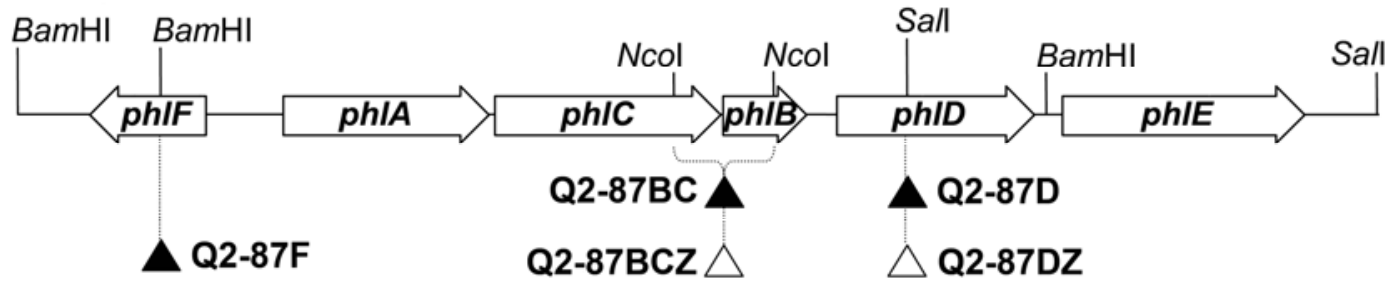

$1 \mathrm{~kb}$

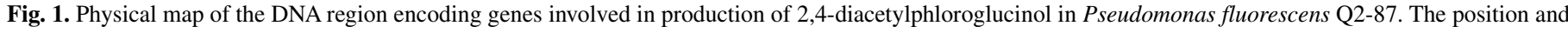

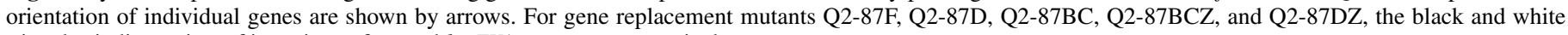
triangles indicate sites of insertions of tet and lacZYA cassettes, respectively. 
The antibiotic was dissolved in methanol $\left(1 \mathrm{mg} \mathrm{ml}^{-1}\right)$ and then further diluted with sterile water. All treatments received the same amount of methanol. Five days prior to challenge inoculation (see below), $13 \mathrm{ml}$ of the antibiotic solution was slowly injected with a syringe and needle into the mix in each pot. Controls consisted of methanol and water or water alone injected into the soil. In some experiments, an SAR treatment was included as a control. For this purpose, three lower leaves of a seedling were infiltrated with $10 \mathrm{mM} \mathrm{MgSO} 4$ containing avirulent $P$. syringae pv. tomato (avrRpt2) at $10^{7} \mathrm{CFU} \mathrm{ml}^{-1}$, using a syringe without a needle (45). All treatments were arranged in a completely randomized design
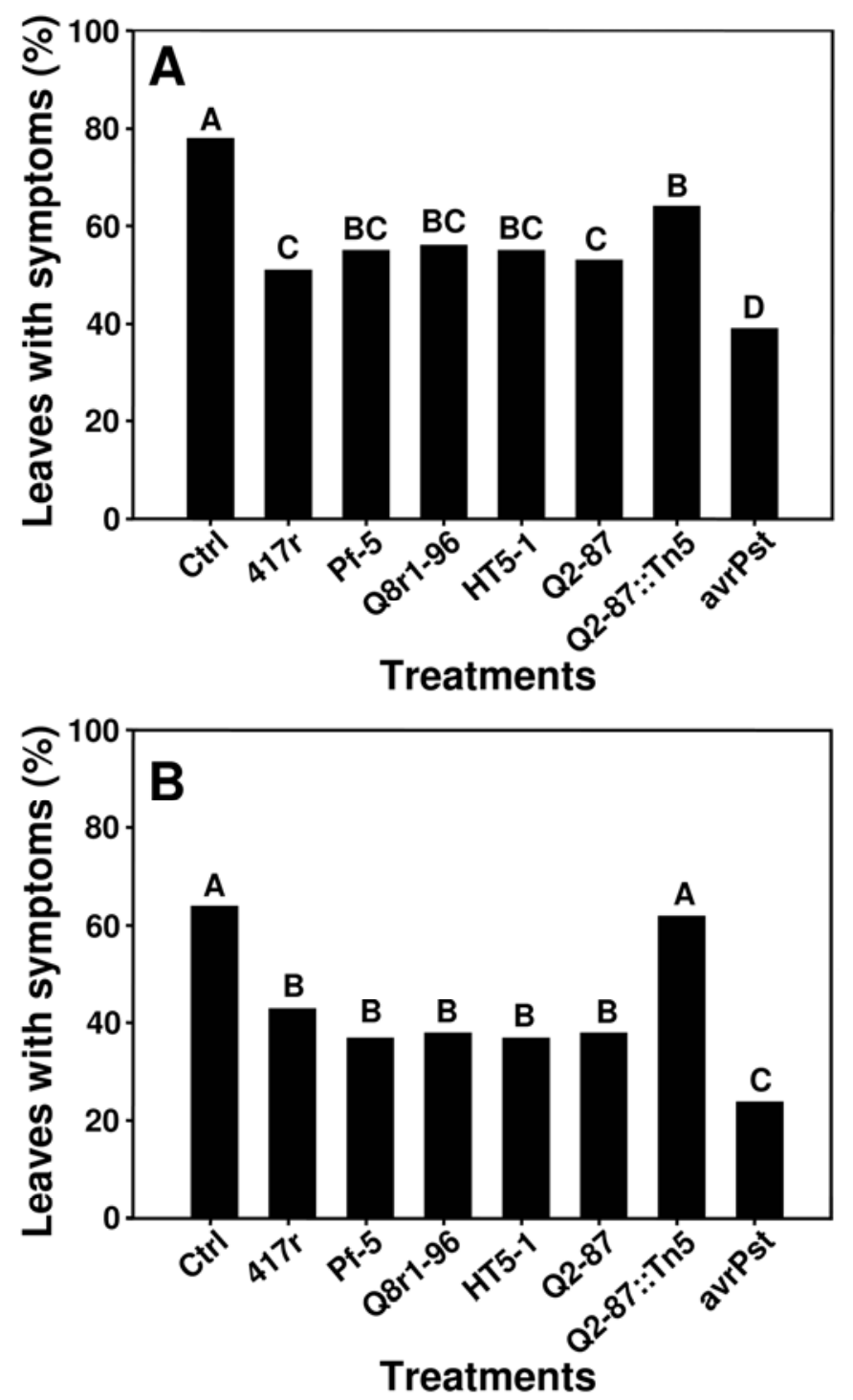

Fig. 2. Induction of systemic resistance in Arabidopsis thaliana Col-0 by 2,4diacetylphloroglucinol-producing Pseudomonas fluorescens strains (Pf-5, genotype A; Q2-87, genotype B; Q811-96, genotype D; and HT5-1, genotype $\mathrm{N}$ ), antibiotic-deficient mutant Q2-87::Tn5-1, and P. fluorescens WCS417r. Two-week-old seedlings were transplanted into a potting soil mix with either $10 \mathrm{mM} \mathrm{MgSO}_{4}(\mathrm{Ctrl}=$ nontreated control $)$ or $5 \times 10^{7}$ bacterial cells $/ \mathrm{g}$ of soil in $10 \mathrm{mM} \mathrm{MgSO}_{4}$. Plants were grown for another 3 weeks and challenge inoculated by dipping the rosette leaves in a suspension of $P$. syringae pv. tomato $\left(1 \times 10^{7} \mathrm{CFU} \mathrm{ml} \mathrm{m}^{-1}\right)$. For the systemic acquired resistance treatment, three lower leaves of a seedling were infiltrated before challenge with $10 \mathrm{mM}$ $\mathrm{MgSO}_{4}$ containing avirulent $P$. syringae pv. tomato (avrRpt2) at $10^{7} \mathrm{CFU} \mathrm{ml}{ }^{-1}$, using a syringe without a needle. Disease severity was evaluated 3 days after challenge inoculation and is expressed as the mean percentage of leaves with necrotic water-soaked symptoms per plant. A and B, Two separate experiments. Within each panel, treatments with the same letter are not significantly different $(P=0.05)$ according to the Fisher's protected least significant difference test. and replicated 20 to 24 times. Each pot served as a treatment replicate. All experiments were performed at least twice with similar results.

Challenge inoculation and disease assessment. Plants were subjected to challenge inoculation 3 weeks after being transplanted. One day before challenge, the plants were subjected to $100 \%$ relative humidity by placing lids on the trays holding the pots, and then kept at $100 \%$ relative humidity after inoculation. Challenge inoculation involved dipping the leaves into a suspension of virulent $P$. syringae pv. tomato $\left(1.0,1.5\right.$, or $2.5 \times 10^{7}$

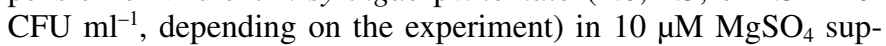
plemented with $0.01 \%$ of the surfactant Silwet L-77. The concentration of $P$. syringae pv. tomato was varied among experiments to alter the severity of disease. The percentage of leaves showing necrotic or water-soaked lesions surrounded by chlorosis were scored 3 or 4 days after challenge inoculation (45).

Root colonization by strains of $\boldsymbol{P}$. fluorescens. At the end of each experiment, the roots of four to six plants per treatment were individually harvested and assayed for the population densities of the introduced bacteria. Each pot was cut open along the sides and the soil mix and roots were carefully removed from the pot. The mix was gently teased apart, leaving only the Arabidopsis roots with tightly adhering soil mix. The roots were severed from the shoots and the entire root system with adhering mix was weighed (fresh root weight) and placed in a 50-ml screw-cap centrifuge tube with $20 \mathrm{ml}$ of $10 \mathrm{mM} \mathrm{MgSO}_{4}$ and $1.25 \mathrm{~g}$ of glass beads $(0.6 \mathrm{~mm}$ in diameter). Tubes were vigorously agitated with a Vortex mixer on high speed, resulting in the roots being fragmented into small pieces. A 1-ml aliquot was removed from each tube and serially diluted, and then $0.1-\mathrm{ml}$ aliquots of each dilution were spread plated in duplicate on plates of KB agar supplemented with ampicillin $\left(40 \mu \mathrm{g} \mathrm{ml}^{-1}\right)$, chloramphenicol $\left(13 \mu \mathrm{g} \mathrm{ml}^{-1}\right)$; and cycloheximide $\left(100 \mu \mathrm{g} \mathrm{m} l^{-1}\right)$, and rifampicin $\left(75 \mu \mathrm{g} \mathrm{ml}^{-1}\right)$ $\left(\mathrm{KB}^{++++}\right)$.

To assess the stability of pMON5122 in the 2,4-DAPG-minus mutants, dilutions of samples containing Q2-87DZ(pMON5122) or Q2-87BCZ(pMON5122) were also plated on $\mathrm{KB}^{+++}$and $\mathrm{KB}$, each supplemented with tetracycline $\left(25 \mu \mathrm{g} \mathrm{ml}^{-1}\right)$. Samples containing strains Q2-87DZ(pPHL5122) or Q2-87BCZ(pPHL5122) were also plated on $\mathrm{KB}$ supplemented with cycloheximide $\left(100 \mu \mathrm{g} \mathrm{ml}^{-1}\right)$, rifampicin $\left(75 \mu \mathrm{g} \mathrm{ml}^{-1}\right)$, and kanamycin $\left(50 \mu \mathrm{g} \mathrm{ml}^{-1}\right)$ or cycloheximide $\left(100 \mu \mathrm{g} \mathrm{ml}^{-1}\right)$ and kanamycin $\left(50 \mu \mathrm{g} \mathrm{ml}^{-1}\right)$.

Data analysis. Data of percentage of diseased leaves and bacterial population densities were arcsine and log transformed, respectively, and subjected to standard analysis of variance followed by Fisher's protected least significant difference test $(P=$ 0.05) using STATISTIX (version 8.0; Analytical Software, St. Paul, MN).

\section{RESULTS}

Suppression of bacterial speck on Col-0 by 2,4-DAPGproducing $\boldsymbol{P}$. fluorescens. 2,4-DAPG-producing wild-type strains Pf-5 (genotype A), Q2-87 (genotype B), Q8r1-96 (genotype D), and HR5-1 (genotype N) applied as a soil treatment consistently and significantly $(P=0.05)$ reduced the percentage of diseased leaves on $A$. thaliana Col-0 challenged with $P$. syringae pv. tomato compared with the noninoculated control. In two separate experiments, the four 2,4-DAPG producers did not differ significantly $(P=0.001)$ (Fig. 2A and B) in ability to reduce disease and were equivalent in disease suppression to strain WCS417r, previously shown to be able to induce resistance in A. thaliana. The introduced 2.4-DAPG producers were isolated from the roots (see below) but not from the leaves (data not shown), suggesting no direct effect of the bacteria on the pathogen but an induction of systemic resistance.

Avirulent $P$. syringae pv. tomato infiltrated into the lower leaves (SAR control) consistently reduced the percentage of diseased 
leaves to a significantly greater extent $(P=0.001)$ than the rhizobacteria applied to the soil (Fig. 2A and B). Throughout the course of this study, the total amount of bacterial speck developing on the Col-0 Arabidopsis plants varied among experiments, and was 78 to $40 \%$ of the leaves of noninduced control plants with symptoms. Within this range of disease, the ability of the bacterial treatments to suppress the disease was not affected by the total amount of disease that developed in each experiment.

Population densities of the five wild-type pseudomonads in the Arabidopsis rhizosphere differed significantly in some experiments (Table 2); however, no strain consistently had a significantly greater or lower density than any other strain (Table 2). For example in experiment 1, Q8r1-96 had a significantly $(P=0.001)$ higher density than Q2-87 but, in experiment 2, the opposite occurred. In all experiments, population densities were always $>\log 6.5 \mathrm{CFU} \mathrm{g}^{-1}$ root (Table 2), a population sufficient to induce resistance (48).

Effect of loss of 2,4-DAPG production on disease suppression in Col-0 by Q2-87 mutants. All phlD or phlCB mutants of Q2-87, constructed by transposon mutagenesis (Q287::Tn5-1) (4) or gene replacement (Q2-87BC, Q2-87BCZ, Q287D, and Q2-87DZ), were deficient in 2,4-DAPG production in vitro, as previously described for Q2-87::Tn5-1 (4) and demonstrated in this study for Q2-87BC, Q2-87BCZ, Q2-87D, and Q287DZ using HPLC analysis (7) (data not shown). All mutants except Q2-87D were used to determine the role of the antibiotic in suppression of $P$. syringae pv. tomato in Arabidopsis.

In nine separate experiments conducted over a 30-month period of time (five shown here), Arabidopsis plants colonized by antibiotic-deficient mutants (Q2-87::Tn5-1, Q2-87BC, Q2-87BCZ, or Q2-87DZ) consistently showed significantly $(P=0.001)$ more disease than plants treated with Q2-87; the amount of disease was either equivalent to that on nontreated control plants or intermediate between the amount of disease on control and Q2-87 treated plants (Figs. 2A and B, 3A and B, and 4A). phlD and phlCB mutants performed similarly in experiments where they were tested together.

$p h l F$ is a regulatory gene in the 2,4-DAPG biosynthetic locus (4) and its disruptions does not result in a loss of 2,4-DAPG production but, rather, an increase. Arabidopsis plants treated with Q2-87F had significantly less disease $(P=0.001)$ than nontreated control or Q2-87::Tn5-1- or Q2-87BC-treated plants (Fig. 4A). Q2-87F and Q2-87 did not differ significantly in ability to suppress disease.
Rhizosphere population densities of the antibiotic-deficient mutants tested for ISR activity (Q2-87::Tn5-1, Q2-87BC, Q2-

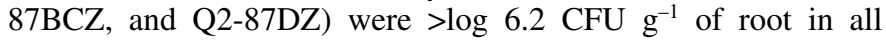
experiments and did not consistently differ from Q2-87 in ability to colonize the rhizosphere (Table 2; experiments 1 to 6). For example, Q2-87 reached a significantly higher density than Q2$87:$ Tn5-1 in experiment $1(P=0.001)$ and experiment $2(P=$ $0.002)$; there was no difference in experiment $3(P=0.932)$; and the density of Q2-87::Tn5-1 was significantly $(P=0.003)$ higher than that of Q2-87 in experiment 4 (Table 2).

Effect of genetic complementation of mutants on disease suppression. The antibiotic-deficient mutants Q2-87DZ and Q287BCZ were genetically complemented with the plasmid pMON5122 or pPHL5122, generating the strains Q2-87DZ (pMON5122), Q2-87BCZ(pMON5122), Q2-87DZ(pPHL5122), and Q2-87BCZ(pPHL5122), respectively, and restoring antibiotic production in the mutants. HPLC analysis demonstrated that mutants complemented with pMON5122 and pPHL5122 produced approximately five times more and four times less antibiotic than Q2-87 in broth cultures (data not shown).

Arabidopsis treated with strains Q2-87BCZ(pMON5122) or Q2-87BCZ(pPHL5122) had significantly $(P=0.001)$ less disease than plants treated with no bacteria, Q2-87BC, or Q2-87BCZ but an equivalent amount of disease to plants treated with Q2-87 (Fig. 3B). Plants treated with Q2-87DZ(pPHL5122) had significantly $(P=0.001)$ less disease than nontreated plants, Q2-87DZ, or Q287::Tn5-1, and equivalent disease to plants treated with Q2-87. Plants treated with Q2-87DZ(pMON5122) had significantly $(P=$ $0.001)$ less disease than nontreated plants, and an equivalent amount of disease to plants treated with Q2-87, Q2-87DZ, or Q287::Tn5-1 (Fig. 3A). In another experiment (data not shown), plants treated with Q2-87DZ(pMON5122) had significantly less disease than plants treated with the antibiotic-minus mutant.

Rhizosphere population densities of the four genetically complemented mutants were $>\log 6.3$ in all experiments and did not differ significantly from the density of Q2-87 (Table 2). Samples containing mutants complemented with either pPHL5122 or pMON5122 were also plated on media containing kanamycin or tetracycline, respectively. The difference in counts on media with and without kanamycin or tetracycline was used to determine the frequency of cells that retained the plasmids after 3 weeks of growth in the rhizosphere. pPHL5122 was highly stable in the mutants because the counts on media with and without kanamycin were identical. In addition, all colonies transferred from media without kanamycin to media with the antibiotic grew (Table 2;

TABLE 2. Population sizes of introduced wild-type, 2,4-diacetylphloroglucinol mutants and genetically complemented strains in the rhizosphere of Arabidopsis thaliana Col-0 $0^{\mathrm{y}}$

\begin{tabular}{|c|c|c|c|c|c|c|}
\hline \multirow[b]{2}{*}{ Strain } & \multicolumn{6}{|c|}{ Log CFU/g of root } \\
\hline & Exp. 1 & Exp. 2 & Exp. 3 & Exp. 4 & Exp. 5 & Exp. 6 \\
\hline WCS417r & $7.03 \mathrm{a}$ & $6.80 \mathrm{bc}$ & $7.08 \mathrm{a}$ & $6.59 \mathrm{a}$ & $7.46 \mathrm{a}$ & $7.25 \mathrm{a}$ \\
\hline Q8r1-96 & $7.04 \mathrm{a}$ & $6.65 \mathrm{c}$ & $6.99 \mathrm{a}$ & $\ldots$ & $\ldots$ & $\ldots$ \\
\hline Pf-5 & $6.84 \mathrm{ab}$ & $7.11 \mathrm{a}$ & & $\ldots$ & $\ldots$ & $\ldots$ \\
\hline Q2-87 & $6.77 \mathrm{~b}$ & $6.87 \mathrm{~b}$ & $7.01 \mathrm{a}$ & $6.04 \mathrm{c}$ & $6.68 \mathrm{~b}$ & $6.83 \mathrm{abc}$ \\
\hline Q2-87::Tn5-1 & $6.43 c$ & $6.61 \mathrm{c}$ & $7.03 \mathrm{a}$ & $6.33 \mathrm{~b}$ & $7.01 \mathrm{ab}$ & $\ldots$ \\
\hline Q2-87DZ(pMON5122) & $\ldots$ & $\ldots$ & $\ldots$ & $\ldots$ & $6.62 \mathrm{~b}(11.5 \%)^{\mathrm{z}}$ & $\ldots$ \\
\hline Q2-87DZ(pPHL5122) & $\ldots$ & $\ldots$ & $\ldots$ & $\ldots$ & $6.69 \mathrm{~b}(100 \%)^{\mathrm{z}}$ & \\
\hline Q2-87BCZ(pMON5122) & $\ldots$ & $\ldots$ & $\ldots$ & $\ldots$ & $\ldots$ & $6.37 \mathrm{c}(26.4 \%)^{\mathrm{z}}$ \\
\hline Q2-87BCZ(pPHL5122) & $\ldots$ & $\ldots$ & $\ldots$ & $\ldots$ & $\ldots$ & $6.63 \mathrm{bc}(100 \%)^{\mathrm{z}}$ \\
\hline Q2-87F & $\ldots$ & $\ldots$ & $\ldots$ & $6.21 \mathrm{bc}$ & $\ldots$ & \\
\hline$P=$ & 0.0009 & 0.0016 & 0.3918 & 0.0034 & 0.0211 & 0.00182 \\
\hline
\end{tabular}

${ }^{y}$ Means in the same column followed by the same letter are not significantly different $(P=0.05)$ according to Fisher's protected least significant difference test. Population sizes of strains in experiments (Exp.) 1, 2, 5, and 6 correspond to strains shown in Figures 2A, 2B, 3A, and 3B, respectively. Data showing the induction of resistance by strains in experiments 3 and 4 are not shown.

${ }^{\mathrm{z}}$ Percentage of the cells of the complemented mutants retaining pMON5122 or pPHL5122 when the population densities were determined. 
experiments 5 and 6). In contrast, pMON5122 was less stable in Q2-87DZ and Q2-87BCZ. The colony counts of Q287DZ(pMON5122) and Q2-87BC(pMON5122) on media with tetracycline were only 11.5 and $26.4 \%$, respectively, of the counts on media without tetracycline. In addition, the same percentages of colonies transferred from media without tetracycline grew on media with the antibiotic (Table 2; experiments 5 and 6).

Effect of addition of pure 2,4-DAPG into soil. All three concentrations of 2,4-DAPG $(10,100$, and $250 \mu \mathrm{M})$ introduced into the soil mix significantly $(P=0.001)$ reduced the amount of bacterial speck on plants grown in the treated soil compared with
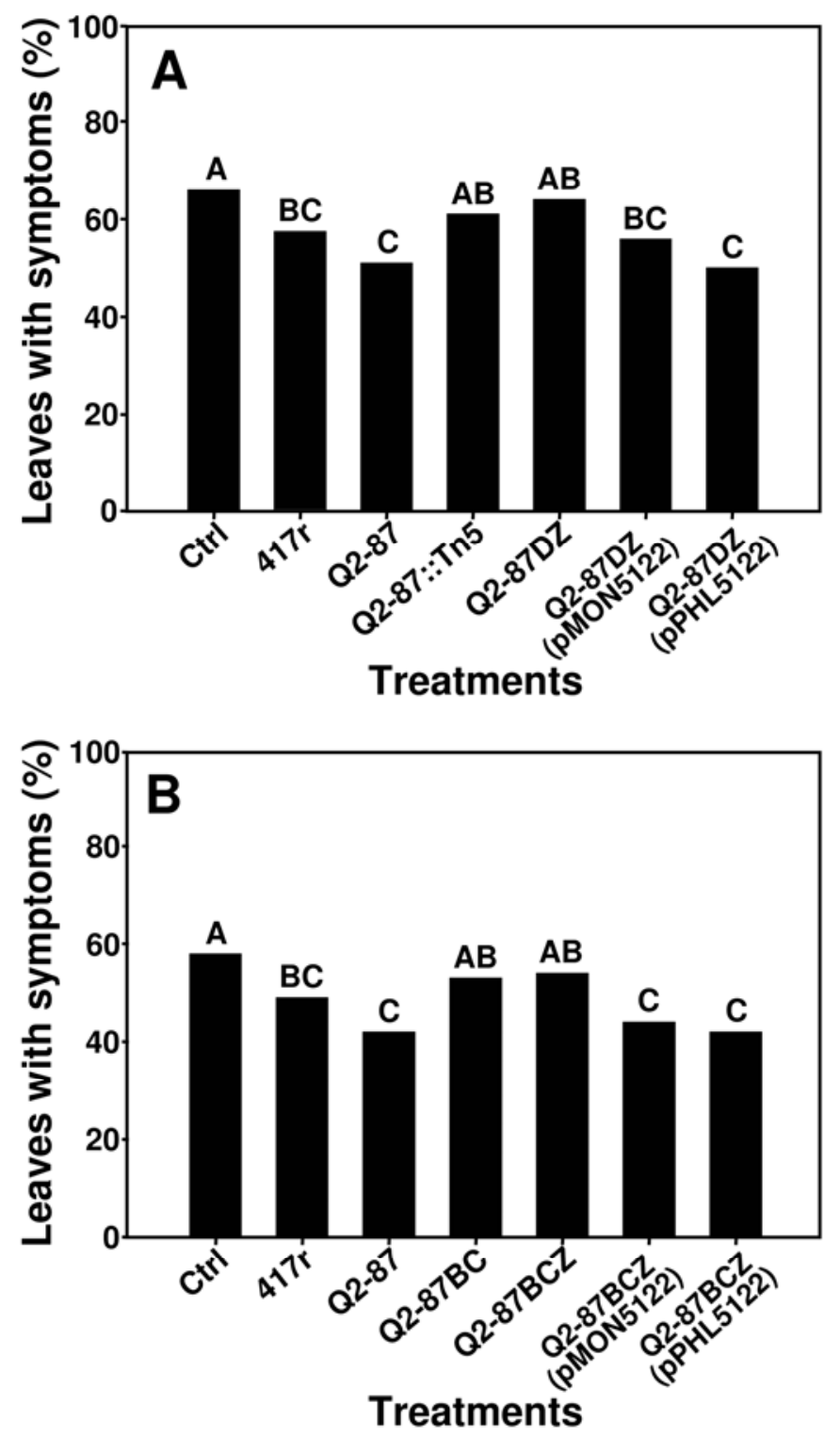

Fig. 3. Induction of systemic resistance in Arabidopsis thaliana Col-0 by 2,4diacetylphloroglucinol-producing strain Pseudomonas fluorescens Q2-87 (genotype B), antibiotic-deficient mutants (Q2-87::Tn5-1, Q2-87BC, Q287BCZ, and Q2-87DZ), mutants Q2-87BCZ and Q2-87DZ genetically complemented with pPMON5122 or pPHL5122, and P. fluorescens WCS417r. Two-week-old seedlings were transplanted into a potting soil mix with either $10 \mathrm{mM} \mathrm{MgSO}_{4}(\mathrm{Ctrl}=$ control$)$ or $5 \times 10^{7}$ bacterial cells g ${ }^{-1}$ of soil in $10 \mathrm{mM}$ $\mathrm{MgSO}_{4}$. Plants were grown for another 3 weeks and challenge inoculated by dipping the rosette leaves in a suspension of $P$. syringae pv. tomato at $\mathbf{A}, 2.5 \times$ $10^{7}$ or $\mathbf{B}, 1.0 \times 10^{7} \mathrm{CFU} \mathrm{ml}^{-1}$. Disease severity was evaluated 3 or 4 days after challenge inoculation and is expressed as the mean percentage of leaves with necrotic water-soaked symptoms per plant. A and B, Two separate experiments. Within each panel, treatments with the same letter are not significantly different $(P=0.05)$ according to the Fisher's protected least significant difference test. plants grown in the mix treated with water only or water + methanol (Fig. 4B). All concentrations of 2,4-DAPG had equivalent ISR activity. The water + methanol treatment significantly $(P=0.001)$ reduced disease compared with the water control.

Disease development in NahG Arabidopsis and npr1, jar1, and etr 1 mutants. To help determine the plant hormone signaling pathway involved in ISR, strain Q2-87 was tested for ISR activity on NahG transgenic Arabidopsis and on nprl-1, jarl, and etrl mutant plants. As in earlier experiments, Q2-87 resulted in less bacterial speck on wild-type accession Col-0 compared with the nontreated control (Table 3). Q2-87-treated NahG plants had sig-
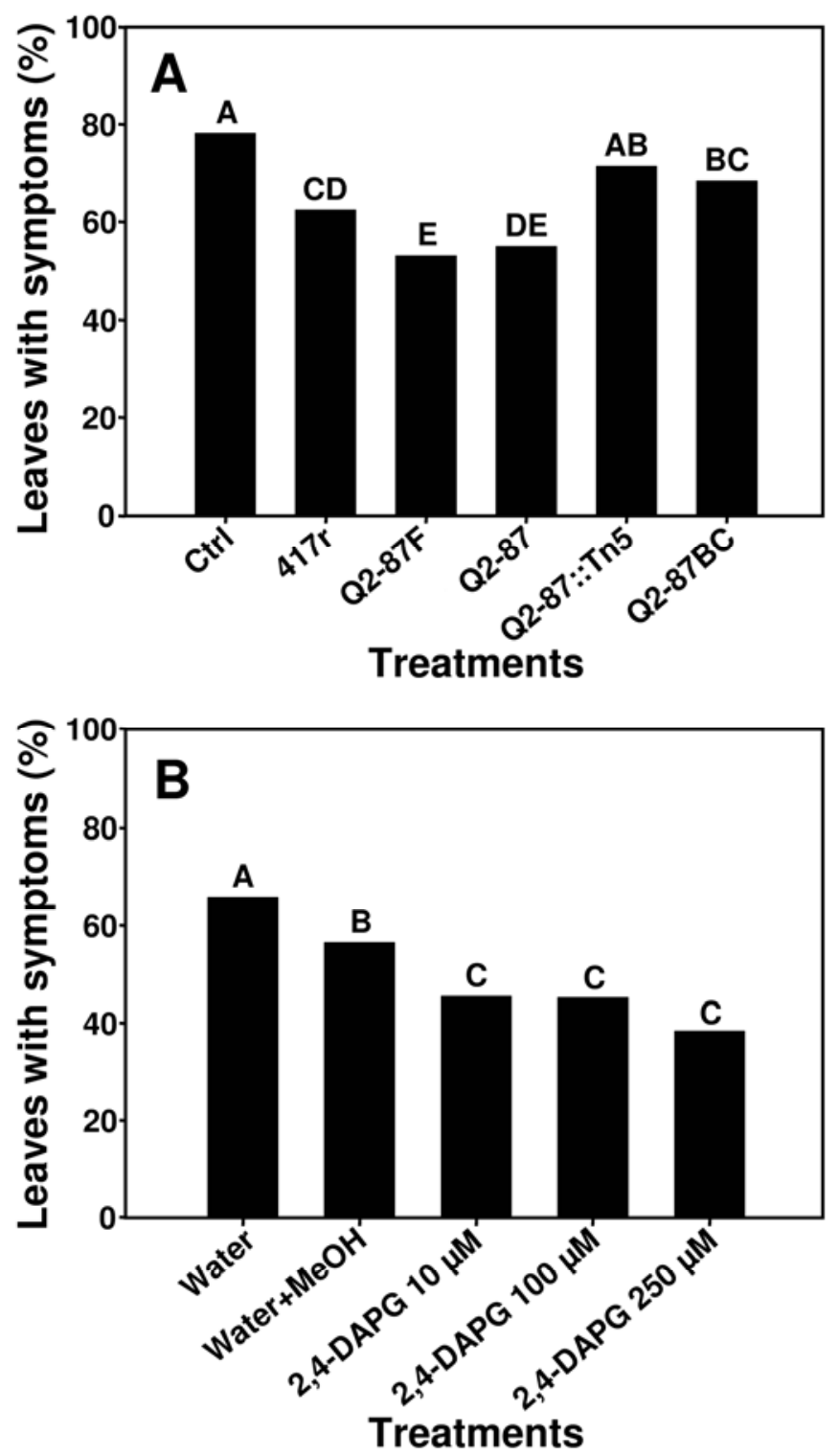

Fig. 4. Induction of systemic resistance in Arabidopsis thaliana Col-0 by A, 2,4-diacetylphloroglucinol (2,4-DAPG)-producing strain Pseudomonas fluorescens Q2-87 (genotype B), antibiotic-deficient mutants (Q2-87::Tn5-1 and Q2-87BC), and regulatory mutant Q2-87F, P. fluorescens WCS417r; and B, pure 2,4-DAPG applied into the soil $(10,100$, and $250 \mu \mathrm{M})$. Two-week-old seedlings were transplanted into a potting soil mix with either $10 \mathrm{mM} \mathrm{MgSO}$ $(\mathrm{Ctrl}=$ nontreated control $)$ or bacterial cells at $5 \times 10^{7} \mathrm{~g}^{-1}$ of soil in $10 \mathrm{mM}$ $\mathrm{MgSO}_{4}$. Plants were grown for another 3 weeks and challenge inoculated by dipping the rosette leaves in a suspension of $P$. syringae pv. tomato $(1.0 \times$ $10^{7} \mathrm{CFU} \mathrm{ml} \mathrm{m}^{-1}$ ). Prior to challenge, 2,4-DAPG dissolved in a methanol-water mix was injected into the soil with a syringe. Equal amounts of methanolwater or water alone were injected as controls (B). Disease severity is expressed as the mean percentage of leaves with necrotic water-soaked symptoms per plant. Treatments with the same letter are not significantly different $(P=0.05)$ according to the Fisher's protected least significant difference test. 
nificantly less disease then nontreated plants. Q2-87 was unable to suppress disease on the nprl-1, jarl, and etrl Arabidopsis mutants (Table 3), suggesting that the signal transduction pathway was ET and JA dependent.

\section{DISCUSSION}

We demonstrated the ability of 2,4-DAPG-producing $P$. fluorescens strains, applied to a potting soil mix, to induce systemic resistance in the leaves of $A$. thaliana against $P$. syringae pv. tomato. 2,4-DAPG producers (Pf-5, Q2-87, Q8r1-96, and HT1-5), representing four genotypes $(\mathrm{A}, \mathrm{B}, \mathrm{D}$, and $\mathrm{N})$ and isolated from three distinct geographic regions of the United States (Texas, Washington State, and Minnesota) were equally effective at inducing resistance. In addition, the 2,4-DAPG producers showed consistent ISR activity over a wide range of disease severity $(40 \%$ [moderate] to $80 \%$ [high] of the leaves with symptoms). We ruled out the possibility of direct interactions between the 2,4-DAPG producers and $P$. syringae pv. tomato by showing that the $2,4-$ DAPG producers did not colonize the leaves and that disease was not suppressed by Q2-87 colonizing the roots of $n p r 1-1$, etrl, and jarl mutants of $A$. thaliana Col-0. We confirmed the ISR assay performance as previously described (45) by including strain WCS417r as a positive control in most of the experiments. In addition, SAR, induced by infiltrating avirulent $P$. syringae pv. tomato into the leaves, was included as a control and shown to reduce the amount of disease more than rhizobacteria-mediated ISR, which is characteristic of SAR (26).

Our findings are consistent with those of Iavicoli et al. (21), who demonstrated that the 2,4-DAPG producer CHA0 (genotype A, isolated from a Swiss suppressive soil) induced systemic resistance in $A$. thaliana against $H$. arabidopsidis and implicated 2,4-DAPG as the key determinant of the activity. Given the breadth of the 2,4-DAPG producers now shown to have ISR activity, we think that this trait is common, if not universal, among this important group of biocontrol rhizobacteria.

Previously, Raaijmakers et al. (48) reported that a threshold population density of $10^{5} \mathrm{CFU} \mathrm{g^{-1 }}$ of root was required for induction of resistance in radish by $P$. fluorescens WCS374 against Fusarium wilt caused by Fusarium oxysporum f. sp. raphani. The same threshold population density was required for direct suppression of $G$. graminis var. tritici in the wheat rhizosphere by P. fluorescens Q2-87. In the current study, the population densities of the introduced rhizobacteria in the Arabidopsis rhizosphere were consistently above $10^{6} \mathrm{CFU} \mathrm{g}{ }^{-1}$ of root, which is thought to be sufficient to induce resistance (48). Among the wild-type strains tested, rhizosphere population densities differed significantly $(P=0.05)$ within certain experiments but those differences were not consistent across experiments and, thus, were not biologically relevant. The lack of differences in colonization of the Arabidopsis rhizosphere, even for Q8r1-96, Pf-5, and Q287 (known to differ significantly in colonization of pea and wheat), is not unexpected because the ISR assay utilizes an autoclaved potting soil mix and very high initial doses of rhizobacteria to insure maximum colonization of the roots.

We used a genetic approach, commonly known as "Molecular Koch's Postulates" (35), to determine the role of 2,4-DAPG in the
ISR activity of Q2-87. We selected Q2-87 as a representative 2,4DAPG producer for this portion of the study for several reasons: it is a well-described biocontrol agent (43) with 2,4-DAPG production as the key mechanism of disease suppression $(18,63)$; it is part of ARDRA group 2, which contains 20 of the 22 known genotypes of 2,4-DAPG producers; it is the source of the first 2,4DAPG biosynthetic locus cloned and sequenced; and it readily produces the antibiotic in the rhizosphere $\left(0.62 \mathrm{ng}\right.$ per $\left.10^{5} \mathrm{CFU}\right)$ (47). Five separate mutants of Q2-87 (Q2-87::Tn5-1, Q2-87BC, Q2-87D, Q2-87BCZ, and Q2-87DZ), constructed with different approaches, and with mutations in either $p h l D$ or spanning $p h l C B$, were deficient in 2,4-DAPG production. All four of the mutants selected for testing in the ISR assay consistently resulted in significantly $(P=0.05)$ less control of $P$. syringae pv. tomato than Q2-87 when applied to the soil mix. Rhizosphere population densities of the 2,4-DAPG deficient mutants were consistently above $10^{6} \mathrm{CFU} \mathrm{\textrm {g } ^ { - 1 }}$ of root and, although, there were significant $(P=0.05)$ differences among the populations of Q2-87 and the mutants, the differences were not consistent and, thus, not biologically relevant.

Somewhat unexpected was the variability in ISR activity of an individual mutant among the experiments. For example in the experiment shown in Figure 2B, the amount of disease on plants treated with Q2-87::Tn5-1 was equivalent to that on the nontreated control plants but, in the experiment shown in Figure 2A, disease severity on plants treated with this mutant was intermediate between that on the noncontrol and Q2-87-treated plants. These results suggest the possibility of a second determinant of ISR associated with Q2-87 that may not be consistently expressed in the rhizosphere. Multiple determinates of ISR are known to be associated with other ISR-inducing rhizobacteria $(3,40)$ and, when more than one determinant is strongly expression in situ, the use of a genetic approach to determine the role of a single determinant can be complicated.

To fulfill Molecular Koch's Postulates, the 2,4-DAPG-deficient mutants Q2-87BCZ and Q2-87DZ were genetically complemented with pMON5122 or pPHL5122, which resulted in four mutants (Q2-87BCZ/pMON5122, Q2-87DZ/pMON5122, Q287BCZ/pPHL5122, and Q2-87DZ/pPHL5122) restored in 2,4DAPG production and concomitantly restored (partially or completely) in ISR activity. Rhizosphere population densities of the mutants were consistently above $10^{6} \mathrm{CFU} \mathrm{\textrm {g } ^ { - 1 }}$ of root. Again, although there were significant $(P=0.05)$ differences in population densities among Q2-87, mutants, and complemented strains, those differences were not consistent.

We were surprised, at first, by the performance of the complemented mutant Q2-87DZ(pMON5122), which produced four times as much 2,4-DAPG as Q2-87 in vitro yet was only partially restored in ISR activity in one of the experiments (disease ratings intermediate between the wild type and Q2-87DZ). This inconsistency may be explained by the rhizosphere population data, which showed that, although the population density was log 6.6 $\mathrm{CFU} \mathrm{g} \mathrm{g}^{-1}$ of root for this strain at the end of the experiment, only $11.5 \%$ of the cells retained the plasmid and, thus, the ability to produce 2,4-DAPG. Interestingly however, twice as many (26.4\%) cells of Q2-87BCZ/pMON5122) retained the plasmid. In contrast, pPHL5122 was very stable in both mutants. The

TABLE 3. Induction of systemic resistance in Arabidopsis thaliana Col-0, NahG transgenic, and npr1-1, jarl, and etr1 mutants by Pseudomonas fluorescens Q2-87

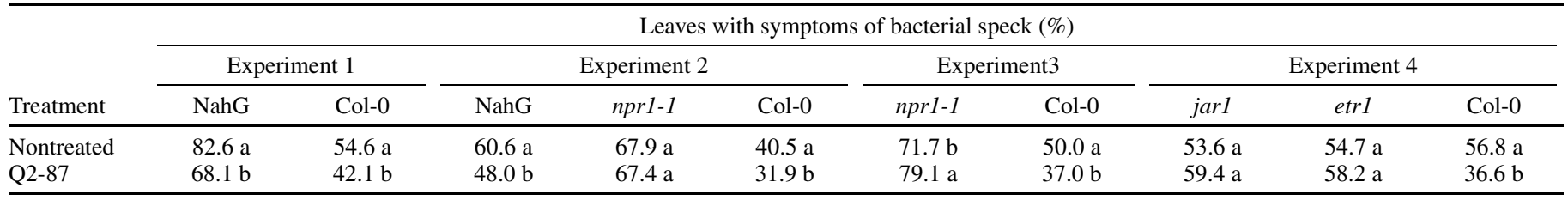

${ }^{\mathrm{z}}$ Means in the same column followed by the same letter are not significantly different $(P=0.05)$ according to Fisher's protected least significant difference test. 
basis for this difference in stability of the two plasmids is not understood.

To complement the findings generated with the completion of Molecular Koch's Postulates, we applied chemically synthesized 2,4-DAPG to the soil in pots with noninoculated plants prior to challenge with $P$. syringae pv. tomato. At all three concentrations tested $(10,100$, and $250 \mu \mathrm{M})$, the antibiotic reduced disease compared with the water control and the water + methanol control and Q2-87, supporting a role for the antibiotic as a determinant of ISR.

In $A$. thaliana, the ISR activity induced by $P$. fluorescens WCS417r operates through a signal transduction pathway that is ET and JA dependent and depends on NPR1 (46). To begin to understand whether Q2-87-induced activity functions through a pathway similar to that induced by WCS417r, we tested Q2-87 on transgenic NahG plants and nprl-1, etrl, and jarl mutants. Q2-87 induced resistance on NahG plants, indicating that ISR is not SA dependent, but Q2-87 had no ISR activity on nprl-1, etrl, and jarl plants. Collectively, these results suggest a pathway similar to that induced by WCS417r. Iavicoli et al. (21) reported that CHA0-induced ISR in A. thaliana against $H$. arabidopsidis functioned through the ET- and JA-dependent pathway. However, WCS417r and CHA0 showed differential responses on etr1-1 and ein2-1 mutants, indicating some differences in the pathways. On the etrl mutant, Q2-87 behaved similarly to WCS417r. Most surprisingly, however, Iavicoli et al. (21) reported that the application of pure 2,4-DAPG induced resistance in npr1-1 and jar1-1, suggesting that the antibiotic induces resistance through a different pathway than CHA0. Further research with a wider collection of Arabidopsis mutants is needed to fully elucidate whether the steps in the signal transduction pathway activated by Q2-87 are identical to the steps induced by WCS417r or CHA0, or if they diverge in some way from the steps induced by these two strains. Future work also will focus on this question, and on the activity of the pure antibiotic on ISR.

It is now clear that some plant species select and support specific populations of 2,4-DAPG producers as a method to defend themselves against certain soilborne pathogens (64). The best examples of this are the take-all decline (TAD) soils in Washington State and The Netherlands $(12,49)$, the black root rotsuppressive soils in Switzerland $(51,65)$, and the Fusarium wiltsuppressive soil in Mt. Vernon, WA (30). In these and other soils, studies have focused on the direct antagonism of the 2,4-DAPG producers on certain target pathogens. Our current study and those of Iavicoli et al. (21) and Siddiqui and Shaukat (56) strongly suggest a wider role for 2,4-DAPG producers in enhancing the basal resistance to foliar and root pathogens in plants growing in natural and agricultural ecosystems. This hypothesis is supported by the following: (i) certain crop species and genotypes of 2,4-DAPG producers show a mutual preference for each other in the rhizosphere (29-31); (ii) 2,4-DAPG producers occur on roots at population densities above the threshold $\left(10^{5} \mathrm{CFU} \mathrm{g}^{-1}\right.$ of root) necessary for induction of resistance, especially when the plant is grown in monoculture $(29,31,47)$; and (iii) $2,4-\mathrm{DAPG}$ has been isolated from the rhizosphere of several plant species $(5,47)$ grown in natural soil. Studies are currently under way to determine the breadth of activity of 2,4-DAPG-based suppressiveness in TAD soils against a broad range of foliar and root pathogens.

\section{ACKNOWLEDGMENTS}

D. M. Weller was the recipient of fellowships from the "Willie Commelin Scholten" Foundation and the Organisation for Economic Cooperation and Development (OECD), which supported the work. He is deeply grateful to his co-authors at Utrecht University for allowing him to work in their facilities and for their advice, assistance, and support in conducting this research. We thank R. F. Bonsall for HPLC analysis of 2,4-DAPG production and N. D. Weller for assistance with ISR assays.

\section{LITERATURE CITED}

1. Audenaert, K., Pattery, T., Cornelis, P., and Höfte, M. 2002. Induction of systemic resistance to Botrytis cinerea in tomato by Pseudomonas aeruginosa 7NSK2: Role of salicylic acid, pyochelin, and pyocyanin. Mol. Plant-Microbe Interact. 15:1147-1156.

2. Ausubel, F. M., Brent, R., Kingston, R. E., Moore, D. D., Seidman, J. G., Smith, J. A., and Struhl, K., eds. 1995. Short Protocols in Molecular Biology. J. Wiley and Sons, New York.

3. Bakker, P. A. H. M., Pieterse, C. M. J., and Van Loon, L. C. 2007. Induced systemic resistance by fluorescent Pseudomonas spp. Phytopathology 97:239-243.

4. Bangera, M. G., and Thomashow, L. S. 1999. Identification and characterization of a gene cluster for synthesis of the polyketide antibiotic 2,4-diacetylphloroglucinol from Pseudomonas fluorescens Q2-87. J. Bacteriol. 181:3155-3163.

5. Bergsma-Vlami, M., Prins, M. E., and Raaijmakers, J. M. 2005. Influence of plant species on population dynamics, genotypic diversity and antibiotic production in the rhizosphere by indigenous Pseudomonas spp. FEMS Microbiol. Ecol. 52:59-69.

6. Bigirimana, J., and Höfte, M. 2002. Induction of systemic resistance to Colletotrichum lindemuthianum in bean by a benzothiadiazole derivative and rhizobacteria. Phytoparasitica 30:159-168.

7. Bonsall, R. F., Weller, D. M., and Thomashow, L. S. 1997. Quantification of 2,4-diacetylphloroglucinol produced by fluorescent Pseudomonas spp. in vitro and in the rhizosphere of wheat. Appl. Environ. Microbiol. 63:951-955

8. Cronin, D., Moënne-Loccoz, Y., Fenton, A., Dunne, C., Dowling, D. N., and O'Gara, F. 1997. Role of 2,4-diacetylphloroglucinol in the interaction of the biocontrol pseudomonad strain F113 with the potato cyst nematode Globodera rostochiensis. Appl. Environ. Microbiol. 63:1357-1361.

9. De La Fuente, L., Mavrodi, D. V., Landa, B. B., Thomashow, L. S., and Weller, D. M. 2006. phlD-based genetic diversity and detection of genotypes of 2,4-diacetylphloroglucinol-producing Pseudomonas fluorescens. FEMS Microbiol. Ecol. 56:64-78.

10. De Meyer, G., Capieau, K., Audenaert, K., Buchala, A., Métraux, J. P., and Höfte, M. 1999. Nanogram amounts of salicylic acid produced by the rhizobacterium Pseudomonas aeruginosa 7NSK2 activate the systemic acquired resistance pathway in bean. Mol. Plant-Microbe Interact. 12:450458.

11. De Souza, J. T., Arnould, C., Deulvot, C., Lemanceau, P., GianinazziPearson, V., and Raaijmakers, J. M. 2003. Effect of 2,4-diacetylphloroglucinol on Pythium: Cellular responses and variation in sensitivity among propagules and species. Phytopathology 93:966-975.

12. De Souza, J. T., Weller, D. M., and Raaijmakers, J. M. 2003. Frequency, diversity, and activity of 2,4-diacetylphloroglucinol-producing fluorescent Pseudomonas spp. in Dutch take-all decline soils. Phytopathology 93:54-63.

13. De Vleesschauwer, D., Djavaheri, M., Bakker, P. A. H. M., and Höfte, M. 2008. Pseudomonas fluorescens WCS374r-induced systemic resistance in rice against Magnaporthe oryzae is based on pseudobactin-mediated priming for a salicylic acid-repressible multifaceted defense response. Plant Physiol. 148:1996-2012.

14. Doornbos, R. F., Geraats, B. P. J., Kumamae, E. E., Van Loon L. C., and Bakker, P. A. H. M. 2011. Effects of jasmonic acid, ethylene and salicylic acid signaling on the rhizosphere community of Arabidopsis thaliana. Mol. Plant-Microbe Interact. 24:395-407.

15. Duffy, B. K., and Défago, G. 1997. Zinc improves biocontrol of Fusarium crown and root rot of tomato by Pseudomonas fluorescens and represses the production of pathogen metabolites inhibitory to bacterial antibiotic biosynthesis. Phytopathology 87:250-1257.

16. Enderle, P. J., and Farwell, M. A.1998. Electroporation of freshly plated Escherichia coli and Pseudomonas aeruginosa cells. Biotechniques 25:954-958.

17. Fenton, A. M., Stephens, P. M., Crowley, J., O'Callaghan, M., and O'Gara, F. 1992. Exploitation of gene(s) involved in 2,4-diacetylphloroglucinol biosynthesis to confer a new biocontrol capability to a Pseudomonas strain. Appl. Environ. Microbiol. 58:3873-3878.

18. Harrison, L. A., Letendre, L., Kovacevich, P., Pierson, E. A., and Weller, D. M. 1993. Purification of an antibiotic effective against Gaeumannomyces graminis var. tritici produced by a biocontrol agent, Pseudomonas aureofaciens. Soil Biol. Biochem. 25:215-221.

19. Hoagland, D. R., and Arnon, D. I. 1938. The water-culture method for growing plants without soil. Calif. Agric. Exp. Stn. Circ. 347:36-39.

20. Howell, C. R., and Stipanovic, R. D. 1979. Control of Rhizoctonia solani on cotton seedlings with Pseudomonas fluorescens and with an antibiotic produced by the bacterium. Phytopathology 69:480-482 .

21. Iavicoli, A., Boutet, E., Buchala, A., and Métraux, J. P. 2003. Induced systemic resistance in Arabidopsis thaliana in response to root inoculation with Pseudomonas fluorescens CHA0. Mol. Plant-Microbe Interact. 16:851-858. 
22. Kamei, Y., and Isnansetyo, A. 2003. Lysis of methicillin-resistant Staphylococcus aureus by 2,4-diacetylphloroglucinol produced by Pseudomonas sp. AMSN isolated from a marine alga. Int. J. Antimicrobiol. Agents 21:71-74.

23. Keel, C., Schnider, U., Maurhofer, M., Voisard, C., Burger, D., Haas, D., and Défago G. 1992. Suppression of root diseases by Pseudomonas fluorescens CHA0: Importance of the bacterial secondary metabolite 2,4diacetylphloroglucinol. Mol. Plant-Microbe Interact. 5:4-13.

24. Keel, C., Weller, D. M., Natsch, A., Défago, G., Cook, R. J., and Thomashow, L. S. 1996. Conservation of the 2,4-diacetylphloroglucinol biosynthesis locus among fluorescent Pseudomonas strains from diverse geographic locations. Appl. Environ. Microbiol. 62:552-563.

25. King, E. O., Ward, M. K., and Raney, D. E. 1954. Two simple media for the demonstration of phycocyanin and fluorescin. J. Lab. Clin. Med. 44:301-307.

26. Knoester, M., Pieterse, C. M. J., Bol, J. F., and van Loon, L. C. 1999. Systemic resistance in Arabidopsis induced by rhizobacteria requires ethylene-dependent signaling at the site of application. Mol. PlantMicrobe Interact. 8:720-727.

27. Kwak, Y., Bakker, P. A. H. M., Glandorf, D. C. M., Topham, J., Paulitz, T., and Weller, D. M. 2009. Diversity, virulence and 2,4-diacetylphloroglucinol sensitivity of Gaeumannomyces graminis var. tritici isolates from Washington State. Phytopathology 99:472-479.

28. Kwak, Y., Han, S., Thomashow, L. S., Rice, J. T., Paulitz, T. C., Kim, D., and Weller, D. M. 2011. Saccharomyces cerevisiae genome-wide mutant screen for sensitivity to 2,4-diacetylphloroglucinol, an antibiotic produced by Pseudomonas fluorescens. Appl. Environ. Microbiol. 77:1770-1776.

29. Landa, B. B., Mavrodi, D. V., Thomshow, L. S., and Weller, D. M. 2003. Interactions between strains of 2,4-diacetylphloroglucinol-producing Pseudomonas fluorescens in the rhizosphere of wheat. Phytopathology 93:982-994.

30. Landa, B. B., Mavrodi, O.V., Raaijmakers, J. M., McSpadden Gardener, B. B., Thomashow, L. S., and Weller, D. M. 2002. Differential ability of genotypes of 2,4-diacetylphloroglucinol-producing Pseudomonas fluorescens strains to colonize the roots of pea plants. Appl. Environ. Microbiol. 68:3226-3237.

31. Landa, B. B., Mavrodi, O. V., Schroeder, K. L., Allende-Molar, R., and Weller, D. M. 2006. Enrichment and genotypic diversity of phlD-containing fluorescent Pseudomonas spp. in two soils after a century of wheat and flax monoculture. FEMS Microbiol. Ecol. 55:351-368.

32. Leeman, M., den Ouden, F. M., van Pelt, J. A., Dirkx, F. P. M., Steijl, H., Bakker, P. A. H. M., and Schippers, B. 1996. Iron availability affects induction of systemic resistance to Fusarium wilt of radish by Pseudomonas fluorescens. Phytopathology 86:149-155.

33. Leeman, M., Van Pelt, J. A., Den Ouden, F. M., Heinsbroek, M., Bakker, P. A. H. M., and Schippers, B. 1995. Induction of systemic resistance against Fusarium wilt of radish by lipopolysaccharides of Pseudomonas fluorescens. Phytopathology 85:1021-1027.

34. Maurhofer, M., Hase, C., Meuwly, P., Métraux, J. -P., and Défago, G. 1994. Induction of systemic resistance of tobacco to tobacco necrosis virus by the root-colonizing Pseudomonas fluorescens strain CHAO: Influence of gacA and of pyoverdine production. Phytopathology 84:139146.

35. Mavrodi, D. V., Blankenfeldt, W., and Thomashow, L. S. 2006. Phenazine compounds in fluorescent Pseudomonas spp. biosynthesis and regulation. Annu. Rev. Phytopathol. 44:417-445.

36. Mavrodi, D. V., Bonsall, R. F., Delaney, S. M., Soule, M. J., Phillips, G., and Thomashow, L. S. 2001. Functional analysis of genes for biosynthesis of pyocyanin and phenazine-1-carboxamide from Pseudomonas aeruginosa PAO1. J. Bacteriol. 183:6454-6465.

37. Mazzola, M., Funnell, D. L., and Raaijmakers, J. M. 2004. Wheat cultivar-specific selection of 2,4-diacetylphloroglucinol-producing fluorescent Pseudomonas species from resident soil populations. Microbiol. Ecol. 48:338-348.

38. McSpadden Gardener, B., Gutierrez, L. J., Raghavendra, J., Edema, R., and Lutton, E. 2005. Distribution and biocontrol potential of phlD pseudomonads in corn and soybean fields. Phytopathology 95:715-724.

39. McSpadden Gardener, B. B., Schroeder, K. L., Kalloger, S. E., Raaijmakers, J. M., Thomashow, L. S., and Weller, D. M. 2000. Genotypic and phenotypic diversity of phlD-containing Pseudomonas strains isolated from the rhizosphere of wheat. Appl. Environ. Microbiol. 66:1939-1946.

40. Meziane, H., Van der Sluis, I., Van Loon, L. C., Höfte, M., and Bakker, P. A. H. M. 2005. Determinants of Pseudomonas putida WCS358 involved in inducing systemic resistance in plants. Mol. Plant Pathol. 6:177-185.

41. Ongena, M., Jourdan, E., Adam, A., Paquot, M., Brans, A., Joris, B., Arpigny, J. L., and Thonart, P. 2007. Surfactin and fengycin lipopeptides of Bacillus subtilis as elicitors of induced systemic resistance in plants. Environ. Microbiol. 9:1084-1090.
42. Paulsen, I. T., Press, C., Ravel, J., Kobayashi, D. Y., Myers, G. S. A., Mavrodi, D. V., DeBoy, R. T., Seshadri, R., Ren, Q., Madupu, R., Dodson, R. J., Durkin, A. S., Brinkac, L. M., Daugherty, S. C., Sullivan, S. A., Rosovitz, M. J., Gwinn, M. L., Zhou, L., Nelson, W. C., Weidman, J., Watkins, K., Tran, K., Khouri, H., Pierson, E. A., Pierson, L. S., Thomashow, L. S., and Loper, J. E. 2005. Complete genome sequence of the plant commensal Pseudomonas fluorescens Pf-5: Insights into the biological control of plant disease. Nat. Biotechnol. 23:873-878.

43. Pierson, E. A., and Weller, D. M. 1994. Use of mixtures of fluorescent pseudomonads to suppress take-all and improve the growth of wheat. Phytopathology 84:940-947.

44. Pieterse, C. M. J., van Pelt, J. A., van Wees, S. C. M., Ton, J., LéonKloosterziel, K. M., Keurentjes, J. J. B., Verhagen, B. W. M., Knoester, M., van der Sluis, I., Bakker, P. A. H. M., and van Loon, L. C. 2001. Rhizobacteria-mediated induced systemic resistance: Triggering, signalling, and expression. Eur. J. Plant Pathol. 107:51-61.

45. Pieterse, C. M. J., Van Wees, S. C. M., Hoffland, E., Van Pelt, J. A., and Van Loon, L. C. 1996. Systemic resistance in Arabidopsis induced by biocontrol bacteria is independent of salicylic acid accumulation and pathogenesis-related gene expression. Plant Cell 8:1225-1237.

46. Pieterse, C. M. J., Van Wees, S. C. M., Van Pelt, J. A., Knoester, M., Laan, R., Gerrits, H., Weisbeek, P. J., and Van Loon, L. C. 1998. A novel signaling pathway controlling induced systemic resistance in Arabidopsis. Plant Cell 10:1571-1580.

47. Raaijmakers, J. M., Bonsall, R. F., and Weller, D. M. 1999. Effect of population density of Pseudomonas fluorescens on production of 2,4diacetylphloroglucinol in the rhizosphere of wheat. Phytopathology 89:470-475

48. Raaijmakers, J. M., Leeman, M., van Oorschot, M., M. P., van der Sluis, I., Schippers, B., and Bakker, P. A. H. M. 1995. Dose-response relationships in biological-control of Fusarium wilt of radish by Pseudomonas spp. Phytopathology 85:1075-1081.

49. Raaijmakers, J. M., and Weller, D. M. 1998. Natural plant protection by 2,4-diacetylphloroglucinol-producing Pseudomonas spp. in take-all decline soils. Mol. Plant-Microbe Interact. 11:144-152.

50. Raaijmakers, J. M., and Weller, D. M. 2001. Exploiting genotypic diversity of 2,4-diacetylphloroglucinol-producing Pseudomonas spp.: Characterization of superior root-colonizing P. fluorescens strain Q8r1-96. Appl. Environ. Microbiol. 67:2545-2554.

51. Ramette, A., Moënne-Loccoz, Y., and Défago, G. 2003. Prevalence of fluorescent pseudomonads producing antifungal phloroglucinols and/or hydrogen cyanide in soils naturally suppressive or conducive to tobacco black root rot. FEMS Microbiol. Ecol. 44:35-43.

52. Ran, L. X., van Loon, L. C., and Bakker, P. A. H. M. 2005. No role for bacterially produced salicylic acid in rhizobacterial induction of systemic resistance in Arabidopsis. Phytopathology 95:3515-3518.

53. Schweizer, H. P. 1992. Allelic exchange in Pseudomonas aeruginosa using novel ColE1-type vectors and a family of cassettes containing portable oriT and the counter-selectable Bacillus subtilis sacB marker. Mol. Microbiol. 6:1195-1204.

54. Shanahan, P., O'Sullivan, D. J., Simpson, P., Glennon, J. D., and O'Gara, F. 1992. Isolation of 2,4-diacetylphloroglucinol from a fluorescent pseudomonad and investigation of physiological parameters influencing its production. Appl. Environ. Microbiol. 58:353-358.

55. Shapira, S. K., Chou, J., Richaud, F. V., and Casadaban, M. J. 1983. New versatile plasmid vectors for expression of hybrid proteins coded by a cloned gene fused to lacA gene sequences encoding an enzymatically active carboxyl-terminal portion of $\beta$-galactodidase. Gene 25:71-82.

56. Siddiqui I. A., and Shaukat, S. S. 2003. Suppression of root-knot disease by Pseudomonas fluorescens CHA0 in tomato: Importance of bacterial secondary metabolite, 2,4-diacetylpholoroglucinol. Soil Biol. Biochem. 35:1615-1623.

57. Simon, R., Priefer, U., and Puhler, A. 1983. A broad host range mobilization system for in vivo genetic engineering: Transposon mutagenesis in gram negative bacteria. BioTechnology 1:784-791.

58. Tran, H., Ficke, A., Asiimwe, T., Hofte, M., and Raaijmakers, J. M. 2007. Role of the cyclic lipopeptide massetolide A in biological control of Phytophthora infestans and in colonization of tomato plants by Pseudomonas fluorescens. New Phytol. 175:731-742.

59. Van Loon, L. C., Bakker, P. A. H. M., and Pieterse, C. M. J. 1998. Systemic resistance induced by rhizosphere bacteria. Annu. Rev. Phytopathol. 36:453-483.

60. Van Peer, R., Nieman, G. J., and Schippers, B. 1991. Induced resistance and phytoalexin accumulation in biological control of Fusarium wilt of carnation by Pseudomonas sp. strain WCS417r. Phytopathology 81:728734.

61. Van Peer, R., and Schippers, B. 1992. Lipopolysaccharides of plant-growth promoting Pseudomonas sp. strain WCS417r induce resistance in carnation to Fusarium wilt. Neth. J. Plant Pathol. 98:129-139.

62. Van Wees, S. C. M., Van der Ent, S., and Pieterse, C. M. J. 2008. Plant 
immune responses triggered by beneficial microbes. Curr. Opin. Plant Biol. 11:443-448.

63. Vincent, M. N., Harrison, L. A., Brackin, J. M., Kovacevich, P. A., Mukerji, P., Weller, D. M., and Cook, R. J. 1991. Suppression of take-all of wheat by seed treatment with fluorescent pseudomonads. Phytopathology 73:463-469.

64. Weller, D. M., Landa, B. B., Mavrodi, O. V., Schroeder, K. L., De La Fuente, L., Blouin Bankhead, S., Allende Molar, R., Bonsall, R. F., Mavrodi, D. V., and Thomashow, L. S. 2007. Role of 2,4-diacetylphloroglucinol-producing fluorescent Pseudomonas spp. in the defense of plant roots. Plant Biol. 1:4-20.

65. Weller, D. M., Raaijmakers, J. M., McSpadden Gardener, B. B., and
Thomashow, L. S. 2002. Microbial populations responsible for specific soil suppressiveness to plant pathogens. Annu. Rev. Phytopathol. 40:309348.

66. Weller, D. M., van Pelt J. A., Mavrodi D. V., Pieterse C. M. J., Bakker P. A. H. M., and van Loon L. C. 2004. Induced systemic resistance (ISR) in Arabidopsis against Pseudomonas syringae pv. tomato by 2,4-diacetylphloroglucinol (DAPG)-producing Pseudomonas fluorescens. (Abstr.) Phytopathology 94:S108.

67. Whalen, M. C., Innes, R. W., Bent, A. F., and Staskawicz, B. J. 1991. Identification of Pseudomonas syringae pathogens of Arabidopsis and a bacterial locus determining avirulence on both Arabidopsis and soybean. Plant Cell 3:49-59. 